Rodrigues, S.L.; Souza, M. O papel das Governanças na regionalização do turismo. Revista Brasileira de Ecoturismo, São Paulo, v.8, n.2,

\title{
O papel da Governança na regionalização do turismo
}

\section{The Role of Governance in the Regionalization of Tourism}

\author{
Suelen de Leal Rodrigues, Marcelino de Souza
}

\section{RESUMO}

A regionalização do turismo no contexto brasileiro prevê a descentralização e a gestão articulada das instâncias de governanças locais. Portanto, o objetivo do presente texto é analisar o papel da governança de turismo, no contexto da Microrregião Uva e Vinho pertencente à Região turística da Serra Gaúcha. A estrutura de análise empregada está alicerçada no conceito de rede geográfica e suas dimensões organizacional, temporal e espacial. Como procedimentos de investigação foram utilizados dados bibliográficos, documentais e a realização de entrevistas focais envolvendo informantes qualificados. A análise da rede criada Associação de Turismo da Serra Nordeste (Atuaserra) identifica a governança regional como importante instância de mediação entre o público e o privado e reforça o trabalho em rede e a gestão compartilhada como elementos essenciais no desenvolvimento regional do turismo.

PALAVRAS-CHAVE: Governança; Turismo; Regionalização.

\begin{abstract}
The regionalization of tourism in the Brazilian context requires decentralization and articulated management of local governance bodies. Therefore, the objective of this paper is to analyze the role of tourism governance in the context of the Grape and Wine Microregion from the touristic region of Serra Gaucha. The analysis framework employed is based on the concept of geographic network and its organizational, temporal and spatial dimensions. As research procedures, documentary and bibliographic data as well as interviews with qualified subjects were used. The analysis of the network created by Atuaserra, an association of tourism, identifies the regional governance as an important instance of mediation between public and private sectors and reinforces the networking and shared management as essential elements in the regional development of tourism.
\end{abstract}

KEYWORDS: Governance; Tourism; Regionalization. 


\section{Introdução}

A região turística apresenta uma pluralidade de conceitos, mas o entendimento conceitual de região nos programas de planejamento está genericamente ligado à prática de identificar peculiaridades geograficamente definidas.

No contexto brasileiro, o processo de regionalização do turismo teoricamente é pautado na abordagem territorial, que prevê a gestão descentralizada, com a participação dos atores locais no planejamento turístico regional. No Ministério do Turismo a orientação para uma gestão descentralizada, com foco na municipalização das ações teve início em 1994 com o Programa Nacional de Municipalização do Turismo, que orientou as diretrizes para o Programa de Regionalização do Turismo criado em 2004. Atualmente as avaliações realizadas desde a implantação do Programa de Regionalização reforçam a necessidade de incentivar mecanismos de motivação e participação social, tendo como mediador deste processo as governanças regionais de turismo.

Desta forma, o objetivo desse trabalho se detém em analisar o papel da governança Atuaserra presente na microrregião Uva e Vinho da Região turística Serra Gaúcha.

Como procedimentos de investigação foram utilizados dados bibliográficos, documentais e entrevistas semiestruturadas. Partindo da análise de dados secundários, foi estabelecida uma amostragem não probabilística intencional, que identificou sujeitos tipo/ informantes qualificados que pudessem representar e fornecer informações a respeito do caso estudado.

Em atendimento ao objetivo proposto, o presente estudo apresentará no seu tópico primeiro uma breve contextualização da regionalização do turismo, a segunda seção abordará a relevância das governanças locais, a terceira parte apresentará a análise e descrição da rede criada pela Atuaserra e a última seção trará as considerações mais pertinentes identificadas na análise da governança Atuaserra.

\section{Regionalização do turismo}

O processo de regionalização do turismo consiste em um mecanismo de ordenamento espacial, conduzido pelo Estado, com objetivo de planejar a atividade turística. $O$ conceito de região adotado pelo processo de regionalização pode variar de acordo com os objetivos da regionalização. $A$ região como categoria espacial é amplamente discutida na ciência geográfica ora enfatizando os aspectos apenas naturais ou integrando as funções de ordem econômica, política e cultural.

A institucionalização da ciência geográfica como disciplina acadêmica ocorreu no fim do século XIX, de acordo com Corrêa (2010) até a década de 1970 o conceito de região foi tratado sob três acepções, região natural, região culturalmente transformada e região como construção intelectual, criada a partir de propósitos específicos. 
A região natural é identificada por uma combinação de elementos naturais, por exemplo, clima, vegetação e relevo, que articulados resultam em uma paisagem específica. A região culturalmente transformada consiste no conjunto integrado de traços culturais, que configuram em diferentes arranjos produtivos, dialetos e costumes, a região é vivenciada pelos seus habitantes que reconhecem sua existência concreta, por exemplo, região da Serra Gaúcha. A terceira abordagem define a região como construção intelectual, que pode ser entendida sob o viés natural ou cultural, de acordo com o recorte de análise exigido.

No contexto dos estudos geográficos, após a década de 1970, a Geografia agregou novos paradigmas de caráter humanista e cultural. De acordo com Anne Gilbert (1988), citada na obra de Corrêa (2010), três conceitos de região emergiram: região como resistência ao projeto totalizador do capitalismo, ou seja, a região como organização espacial de processos sociais, a região como identificação, em que um grupo simbolicamente se identifica com uma porção espacial, uma região apoiada na filosofia do significado e o terceiro conceito seria a região política onde agem diversos poderes.

De acordo com Santos (2006), a fase pós-moderna é marcada pela revolução técnica e informacional, pautada na acumulação flexível e na descentralização da produção, que são potencializadas pelo dinheiro e pelos capitais. A região no contexto atual, ainda persiste como uma categoria de diferenciação espacial, ou seja, de fragmentação, mas como destacou Corrêa (2010) uma fragmentação articulada.

É neste contexto, que as redes geográficas surgem como elementos de análise das atividades sociais e econômicas, pois são elementos que articulam diferentes regiões e territórios.

Considerando que o turismo possui nitidamente uma manifestação espacial, entender e planejar o ordenamento de suas atividades é de suma importância para o desenvolvimento territorial.

Os conceitos de região, no âmbito dos estudos referentes ao turismo, também possuem distintas classificações. Ao tratar do planejamento turístico dos espaços regionais da Espanha, Ivars (2001) cita a sistematização adotada pela Organização Mundial do Turismo (1995), que define três tipos de regiões turísticas, uma relacionada de acordo com a localização geográfica, outra que faz menção as zonas administrativas de escalas e naturezas variáveis e regiões que podem ser definidas pela combinação de critérios. Explorando outras definições de região turística, Ivars (2001) também fez referência à obra de Lozzato (1990) que tratou da região turística como espaços que concentram certa densidade de turistas e possuem uma imagem característica. Apesar da pluralidade de definições, a região turística, segundo Ivars (2001) tem sido tratada como unidade de planejamento.

No contexto brasileiro, no que se refere à trajetória da Política Nacional de Turismo, o enfoque territorial foi institucionalizado em $1994 \mathrm{com}$ o Programa Nacional de Municipalização do Turismo - PNMT, coordenado pelo então Ministério da Indústria, do Comércio e do Turismo (BRASIL, 2013). Para promover o turismo de forma sustentável, articulando 
ministérios, sociedade civil e o setor empresarial, foi criado, no ano de 2003, - Ministério do Turismo, cuja proposta busca promover a gestão descentralizada e participativa das políticas de turismo. Portanto, para elaboração do Plano Nacional de Turismo (2003-2007), o Ministério do Turismo consultou os secretários estaduais de turismo e as principais instituições e empresas nacionais do segmento turístico.

O Plano Nacional de Turismo (2003-2007) serviu de base para construção do Programa Regionalização do Turismo - Roteiros do Brasil lançado em 2004. As discussões promovidas na construção do Programa de Regionalização possibilitaram ajustes no Plano Nacional do Turismo, que passou a estruturar os macroprogramas com base na noção de território e de arranjos produtivos, para estrutura e diversificação da oferta turística.

As referências conceituais presentes no Programa Regionalização do Turismo definem a regionalização do turismo como

[...] um modelo de gestão de política pública descentralizada, coordenada e integrada, baseada nos princípios da flexibilidade, articulação, mobilização, cooperação intersetorial e interinstitucional e na sinergia de decisões. Regionalizar é transformar a ação centrada na unidade municipal em uma política pública mobilizadora, capaz de provocar mudanças, sistematizar o planejamento e coordenar o processo de desenvolvimento local e regional, estadual e nacional de forma articulada e compartilhada (BRASIL, 2004, p. 9).

De acordo com os critérios de regionalização, o Ministério do Turismo implantou o Programa de Regionalização do Turismo e utilizou como principal estratégia a participação de órgãos colegiados de turismo municipal e estadual, representantes da iniciativa privada, instituições de ensino e o terceiro setor.

Esta metodologia originou a Rede Nacional de Regionalização, composta por atores ligados a atividade turística, com objetivo de estruturar nas regiões e municípios as diretrizes do processo de regionalização. Para governabilidade do processo de regionalização foi criada a "Instância de Governança", organizada a partir das realidades regionais. Outra estratégia determinante para o Programa de Regionalização foi a estruturação do Salão de Turismo-Roteiros do Brasil, que além de ser um espaço de negócios tornou-se um espaço de troca de informações entre os segmentos do setor turístico e desta forma, um espaço de diálogo e avaliação (BRASIL, 2013).

Entre as evoluções e resultados alcançados pelo Programa de Regionalização do Turismo, destaca-se a estratégia de definição dos 65 Destinos Indutores do Desenvolvimento Turístico Regional, de acordo com Brasil (2014, s/p) "os destinos indutores do desenvolvimento turístico regional são aqueles que possuem infraestrutura básica e turística e atrativos qualificados, que se caracterizam como núcleo receptor e/ou distribuidor de fluxos turísticos". A identificação dos destinos indutores foi 
uma meta do Plano Nacional do Turismo 2007-2010, para melhorar a infraestrutura dos locais capazes de distribuir fluxos turísticos e desta forma criar sinergias locais para consolidações de regiões.

O Plano Nacional do Turismo 2007-2010 manteve a estratégia de ampliar o diálogo entre sociedade e poder público, para construção de propostas de redução de desigualdades sociais e desenvolvimento das qualidades regionais.

As avaliações realizadas desde 2004 com a implantação do Programa de Regionalização foram sistematizadas na elaboração do Plano Nacional de Turismo 2013-2016. De acordo com o Ministério do Turismo

Na sua concepção filosófica e conceitual, o Programa de Regionalização do Turismo não sofre alterações. Os ajustes propõem qualificar a concepção estratégica, as ferramentas de gestão e incorporar mecanismos de fomento capazes de provocar e promover concepções inovadoras ao enfrentamento das fragilidades diagnosticadas (BRASIL, 2013, p. 20).

O processo de regionalização, portanto, foi mantido como referência territorial para o planejamento do turismo, desta forma, as premissas que norteiam o Programa de Regionalização do Turismo são: abordagem territorial, integração e participação social, descentralização, sustentabilidade, inovação e competitividade (BRASIL, 2013). A região turística é concebida "como espaço plural e participativo, que amplia as capacidades humanas e institucionais, facilitando as relações políticas, econômicas, sociais e culturais" (BRASIL, 2013, p. 23). Desta forma, a gestão da regionalização turística, hoje presente no território brasileiro assume o compromisso de ser estruturada na gestão compartilhada, onde instâncias locais e regionais possuem um papel de mediadoras do processo de planejamento local com as esferas federais de elaboração de políticas.

Explorando a importância das instâncias locais de planejamento, o próximo tópico abordará a criação e institucionalização de governanças territoriais no processo de regionalização do turismo.

\section{Governança, redes e turismo}

Como já destacado, o processo de regionalização foi alicerçado na premissa de promover um desenvolvimento pautado na abordagem territorial.

A abordagem territorial foi incorporada ao discurso das políticas públicas brasileiras na década de 1990, ganhando força a partir dos anos 2000. Consiste em uma forma de gestão descentralizada, organizada em instâncias de várias escalas de atuação, onde os atores locais devem participar da construção das estratégias de desenvolvimento traçadas para seu território. 
No Ministério do Turismo a orientação para uma gestão descentralizada, tendo como foco a municipalização das ações, se fez presente no Programa Nacional de Municipalização do Turismo lançado em 1994 e que orientou as diretrizes para o Programa de Regionalização do Turismo.

Ao tratar do desenvolvimento local e animação turística Silva (2009), referenciou Bramanti (1999) que abordou os conceitos chaves para o desenvolvimento territorial, sistematizados em elementos como a inovação; learning (aprendizagem); redes; governança.

Na obra de Bramanti (1998) o autor organizou o sistema de desenvolvimento territorial de acordo com a (Figura 1).

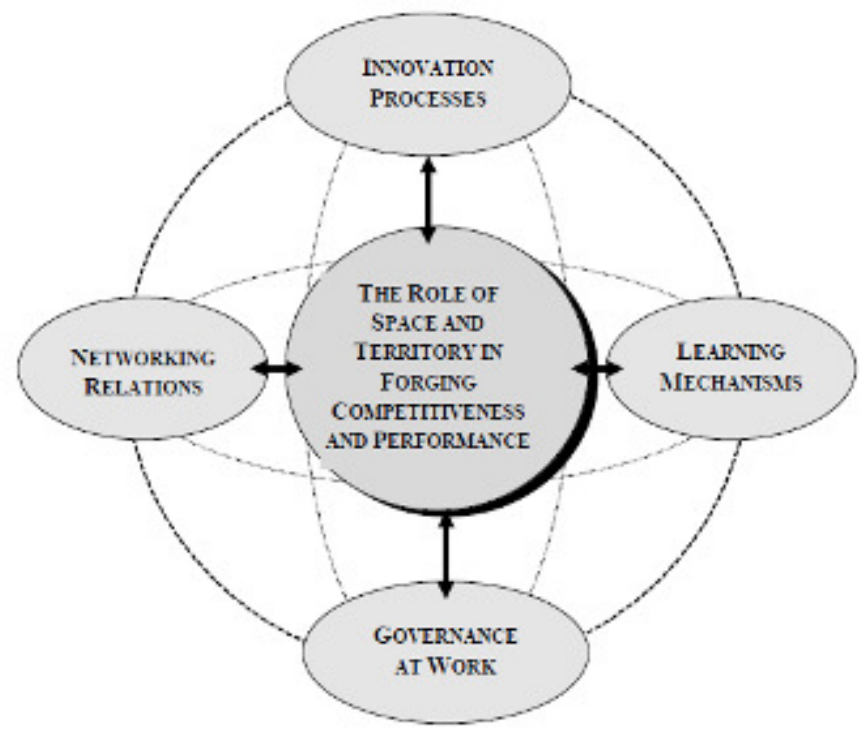

Figura 1: O emergente papel da geografia: uma visão diagramática dos quatro fatores chaves. Fonte: Bramanti (1998).

Figure 1: The emerging role geography: a diagrammatic view of the four building blocks.

Source: Bramanti (1998).

O processo de inovação foi entendido por Bramanti (1998) como "motor of growth", ou seja, seria um processo coletivo que envolve a interação de agentes públicos e privados na construção do know-how, onde a organização territorial assume relevância.

Analisando o processo de inovação Silva (2009), destacou o papel das redes de colaboração na difusão da inovação, uma vez que as redes criam uma coesão territorial, estas podem se constituir em importantes mecanismos de propagação do conhecimento criando conexões em escala global.

A governança dentro da análise territorial do desenvolvimento está situada no processo organizativo 
[...] ou se preferimos, político, que une conceitos (inovação, aprendizagem e redes) na elaboração de uma estratégia de desenvolvimento, e que é dependente da capacidade dos actores e instituições duma região, ou seja, sua densidade institucional (SILVA, 2009, p. 71).

No processo de regionalização do turismo a governança regional foi definida como "uma organização com participação do poder público e dos atores privados dos municípios componentes das regiões turísticas, com o papel de coordenar o Programa em âmbito regional" (BRASIL, 2007a, p. 16).

Entre as estruturas de governança o Ministério do Turismo reconhece que estas podem assumir caráter jurídico diferenciado, como fóruns, conselhos, associações, comitês, consórcio e outros colegiados.

A presente pesquisa contemplou como forma de governança uma associação na forma de Organização da Sociedade Civil de Interesse Público (OSCIP) atuante na microrregião Uva e Vinho da Região turística Serra Gaúcha.

Ao tratar das associações no âmbito do processo de regionalização o Ministério do Turismo contextualizou a formação e função da OSCIP.

A Organização da Sociedade Civil de Interesse Público OSCIP - foi constituída pela Lei no 9.790, de 23 de março de 1999, com o principal objetivo de diferenciar e qualificar, dentro do universo do terceiro setor, as organizações que não têm fins lucrativos e que são voltadas para o interesse público. A qualificação possibilita alguns benefícios, tais como recebimento de auxílios do governo federal (aquisição de equipamentos, por exemplo), trabalho com voluntários, possibilidade de firmar Termo de Parceria, entre outros (BRASIL, 2007a, p. 36).

De acordo com o Ministério do Turismo a vantagem de se constituir uma OSCIP como forma de governança de turismo é ampliar a capacidade técnica e política na proposição de projetos, para articular parceiros e captar recursos.

O principal objetivo de uma instância de governança é instituir uma esfera de gestão articulada com os interesses locais, pois no processo de regionalização do turismo são "responsáveis pela definição de prioridades, pela coordenação das decisões a serem tomadas, pelo planejamento e execução do processo de desenvolvimento do turismo na região turística". (Brasil, 2007a, p.16).

Dentro de uma concepção de gestão compartilhada o Ministério do Turismo delegou para as governanças o papel de intermediar as ações de turismo dos municípios com a esfera estatal. A (Figura 2) mostra a organização da gestão compartilhada. 


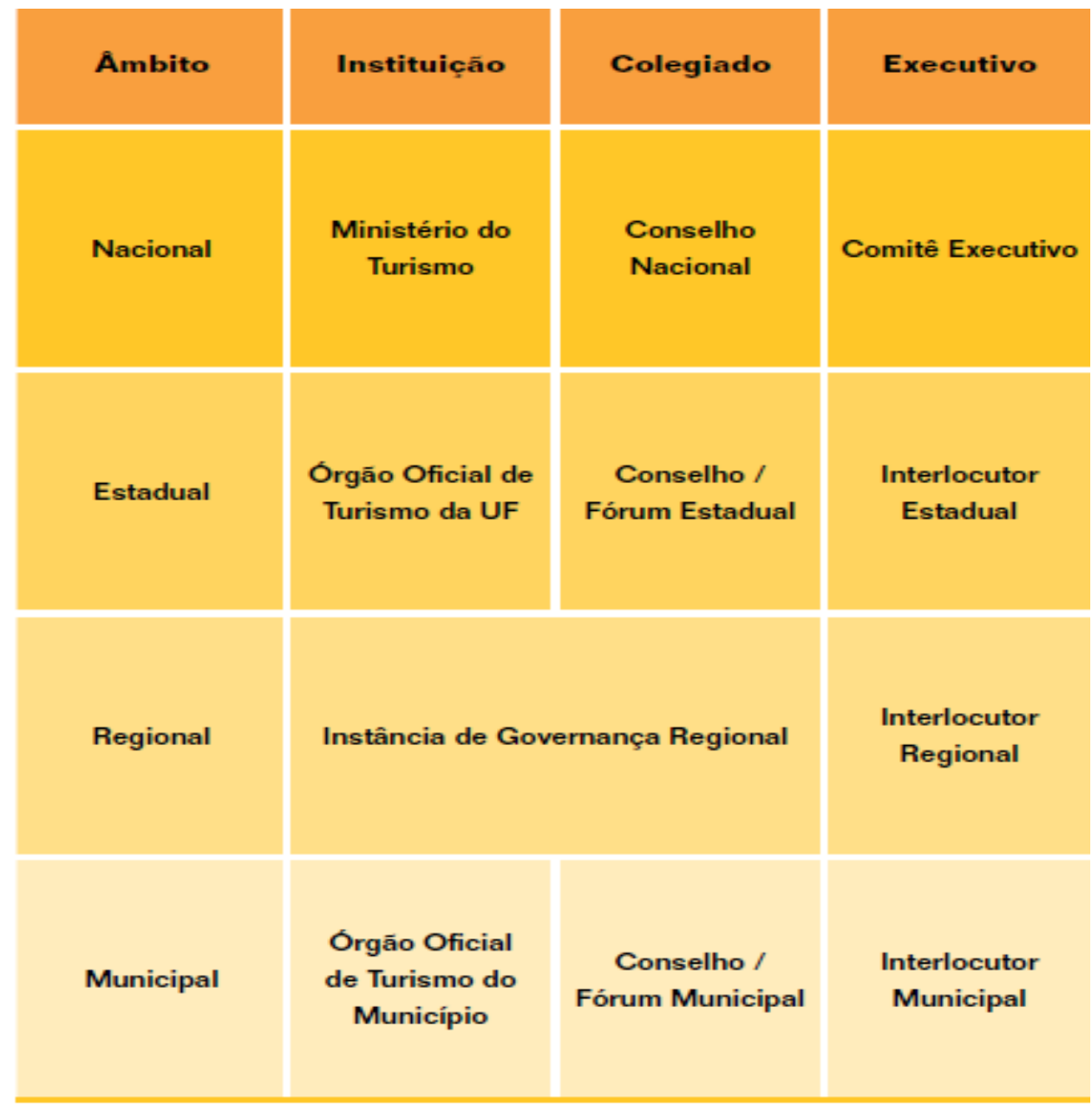

Figura 2: Gestão compartilhada do Programa de Regionalização do Turismo Fonte: Brasil (2013).

Figure 2: Shared Management of Tourism Regionalization Program Source: Brasil (2013).

A interlocução realizada pelas instâncias de governança regional está alicerçada no trabalho articulado em redes. A atuação em rede descentraliza as ações voltadas para o turismo, reduz os custos operacionais da atividade e potencializa as vantagens locais. Desta forma, a organização em rede seria uma importante estratégia para regionalização de áreas turísticas, pois envolve os atores locais no processo de construção da identidade das áreas turísticas e ao mesmo tempo cria vantagens competitivas.

As redes dentro dos estudos relativos ao turismo assumem um caráter organizacional para otimizar vantagens em termos econômicos, sociais e espaciais.

Na prática, o objetivo da Rede para o turismo é fazer com que seus integrantes, as pessoas - físicas ou jurídicas consigam colaborar entre si, compartilhar conhecimentos, capacitar-se, dividir riscos e responsabilidades, conquistar novos mercados, reduzir custos, qualificar produtos $e$ serviços, e ainda desfrutar do acesso às novas tecnologias (BRASIL, 2007b, p. 17). 
Desta forma, a atividade turística articula redes sociais, econômicas e políticas que espacializadas ganham dimensão geográfica, por exemplo, a rede de hotéis, agências e pontos turísticos, são elementos espaciais localizáveis, ou seja, fixos que estabelecem inúmeras relações com os fluxos de informação, capital e poder. Considerando que a rede criada pela atividade turística tem uma dimensão espacial e organizacional, o papel das governanças de turismo, no processo de regionalização, pode ser analisado através do conceito de redes geográficas.

Para a Ciência Geográfica a rede é um elemento intrínseco no estudo das organizações sociais sobre o espaço. Como já mencionado as regiões hoje são fragmentações articuladas por diferentes redes, sociais, políticas, econômicas, culturais e técnicas.

Entre as definições atribuídas à rede, Santos (2006) destacou que pode-se dividir em duas grandes matrizes: "a que considera apenas o seu espaço, a sua realidade material, e uma outra, onde é levado em conta o dado social' (Santos, 2006, p. 176).

A rede é um elemento de conexão e mobilidade de elementos materiais e imateriais, presentes na organização da sociedade desde os povos primitivos, mas a rede moderna surge com advento das técnicas, no processo de divisão territorial do trabalho que aumenta com a revolução "técnica científica e informacional' (Santos, 2006, p. 178) envolvendo todos os avanços da microeletrônica.

Os primeiros estudos que tratam da rede como elemento organizador do espaço surgem no século XIX atrelados ao processo de aceleração dos fluxos de produção e comercialização. Dias (1995) destaca os estudos de Sant Simon (filósofo e economista, francês) em sua obra "Le nouveau Christianisme" onde defendia a criação de um Estado organizado por cientistas e industriais. Parafraseando com o mesmo autor, a partir das ideias presentes nas obras de Sant Simon em 1882 engenheiros como Michel Chevalier e Leon Lallane utilizaram o termo redes para tratar da integração entre redes de comunicação, conectando estradas de ferro, canais fluviais e a circulação de bens materiais e imateriais, como no caso dos capitais. Os capitais ganham destaque com a obra 'Os capitais e a região' do geógrafo Jean Labasse (1955), pois nesta obra o autor mostra a febre bancária na França e a junção do capital com a rede material das vias de comunicação no caso a rede férrea. No Brasil Pierre Monbeig (1952) em seu capítulo intitulado "Regiões e Rede" mostrou a influência dos capitais cafeeiros na organização territorial das redes férreas.

Para o entendimento da dinâmica espacial da economia, modelos de organização espacial foram apresentados por Von Thünen em 1896, Weber (1909). No entanto, foi Walter Christaller a partir da sua obra "Teoria dos Lugares Centrais" de 1933, que propôs uma análise da atividade turística. O avanço técnico do capitalismo e a divisão internacional do trabalho organizaram redes hierarquizadas de distribuição varejista e de serviços, especializadas de acordo com sua importância, criando, desta forma, localidades centrais e periféricas. Transpondo esse entendimento para áreas turísticas, Christaller, em 1963, comparou grandes cidades, que centralizavam produtos e serviços, com áreas periféricas, onde predominava 
a oferta de espaços naturais e concluiu que a atividade turística podia ser uma forma de descentralizar capitais, para áreas que apresentassem condições para o desenvolvimento do turismo. Na teoria de Christaller existe uma relativa imobilidade dos produtos, serviços e consumidores, no entanto, a fase atual do capitalismo, caracterizada pelas técnicas da informação e comunicação, permite a circulação e descentralização de diversos fluxos, através de redes que conectam diferentes regiões.

A rede para Haesbaert (2004) têm um duplo caráter de territorializar e desterritorializar. "o que faz com que os fluxos que por elas circulam tenham um efeito que pode ser ora de sustentação, mais 'interno' ou construtor de territórios, ora de desestruturação, mais 'externo' ou desarticulador de territórios" (Haesbaert, 2004, p. 294).

$\mathrm{Na}$ atualidade existem redes locais e globais, de complementaridade e de sinergia, onde a organização dos fixos e a velocidade dos fluxos estão diretamente ligadas aos centros de decisão, desta forma, os processos de territorialização e desteritorialização são determinados pelos centros hegemônicos de capital e poder.

Buscando entender como se o se organiza territorialmente as governanças de turismo é que foi eleito o conceito de rede para análise aqui proposta.

A definição de rede adotada neste trabalho é a definição apresentada por Corrêa

as redes geográficas são redes sociais espacializadas. São sociais em virtude de serem construções humanas, elaboradas no âmbito de relações sociais de toda ordem, envolvendo poder e cooperação, além daquelas outras esferas da vida (CORRÊA, 2012 p. 200).

A rede geográfica possui múltiplas escalas de ação, portanto, para análise do papel da governança de turismo Atuaserra, foi utilizada uma adaptação das dimensões básicas da rede geográfica proposta por Corrêa (2010).

\section{Análise da Governança Atuaserra}

A análise da atividade turística sob o entendimento da rede geográfica tem por objetivo mostrar uma possibilidade de estudo para as complexas relações criadas pela atividade turística.

Para o presente estudo foi empregada uma adaptação das dimensões da rede geográfica, presente na obra de Corrêa (2010). As dimensões propostas são a organizacional, temporal e espacial (Figura 3). 


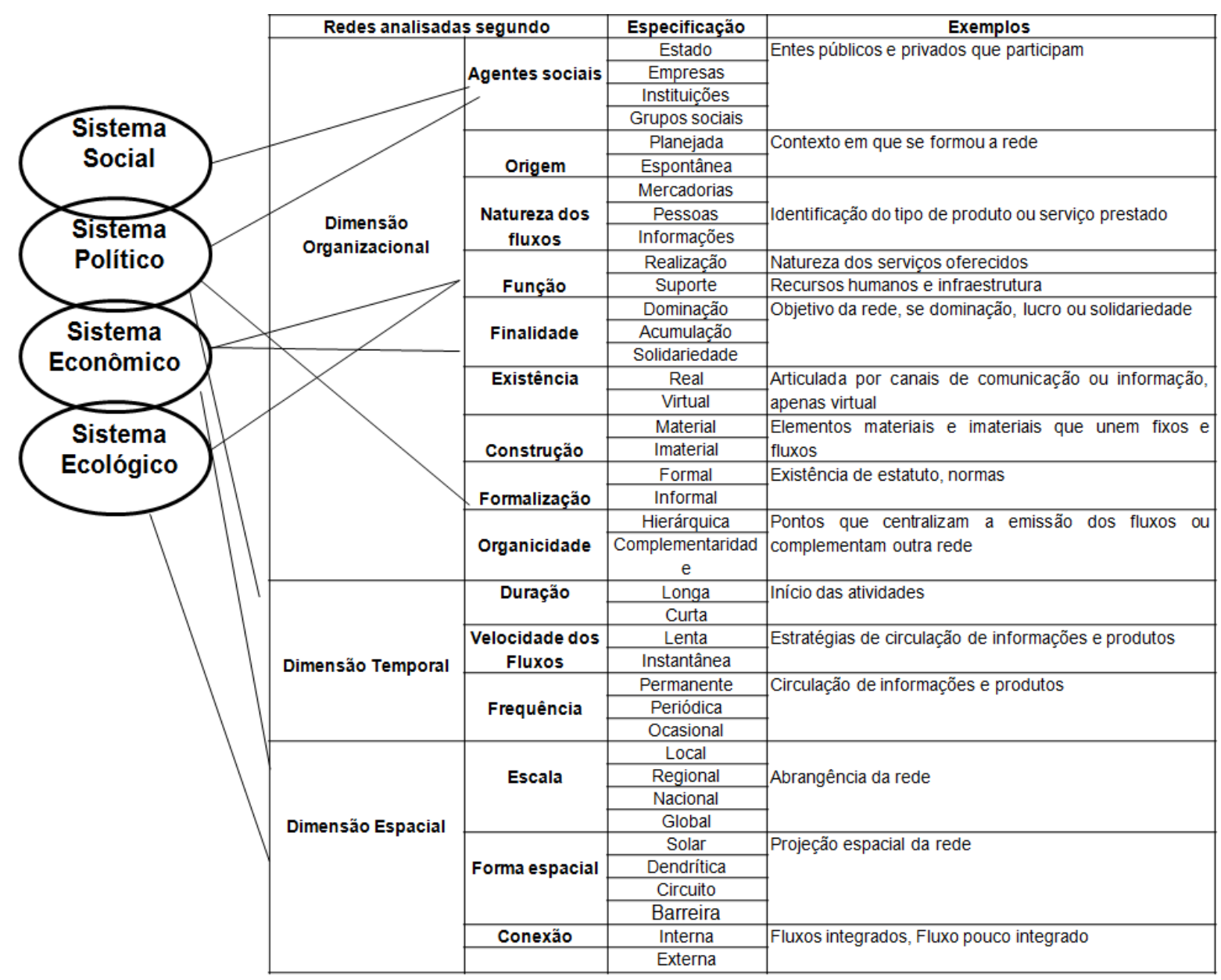

Figura 3: Sistema da atividade turística através das dimensões da rede geográfica Fonte: Corrêa (2010), adaptação do autor.

Figure 3: The tourism system through the dimensions of geographic network Source: Corrêa (2010), adapted by author.

O primeiro tópico proposto consiste na dimensão organizacional, que faz referência aos agentes sociais da rede, a natureza dos fluxos, a função, a finalidade, a existência, a construção, a formalidade e organicidade. A segunda dimensão é a temporal ligada à periodicidade e velocidade dos fluxos e a terceira consiste na dimensão espacial, que retrata a abrangência, a organização e a coesão espacial.

Nossa análise começará pela descrição temporal da Atuaserra, contemplando aspectos presentes na dimensão organizacional.

A Atuaserra surgiu a partir da necessidade de resgatar as ações turísticas na Região da Serra Gaúcha, em específico a Microrregião denominada Uva e Vinho. A referida região até a década de 1950 se destacava como local de veraneio, no entanto, com a construção de rodovias que deram acesso ao litoral, a região deixou de ser um ponto atrativo. As secretarias municipais de turismo, preocupadas com o declínio turístico da região, passaram a realizar reuniões periódicas, com o objetivo de criar ações que alavancassem o turismo na microrregião Uva e Vinho. Segundo a diretora executiva da Atuaserra, em exercício até fevereiro de 2014, existem registros documentais que remetem ao ano de 1972, que 
comprovam que as secretarias de turismo se reuniam sistematicamente para discutir e executar as ações de turismo.

No entanto, a Atuasserra surge oficialmente no ano de 1985, originada da iniciativa de onze secretarias de turismo de Caxias do Sul (primeira sede da Associação), Antônio Prado, Flores da Cunha, Garibaldi, Farroupilha, Bento Gonçalves, Veranópolis, Serafina Corrêa, Nova Prata, Guaporé e São Marcos. Na temporalidade de 10 anos, em 1995 a Atuaserra passou a contar com 19 municípios e em 1997, ampliou seu público, pois incluiu a iniciativa privada, através dos Centros de Indústria e Comércio, Sindicato dos Lojistas, Confederação Nacional de Dirigentes Lojistas, Sindicatos de Hotéis, Restaurantes, Bares e Similares da Região. Portanto, os agentes sociais que fazem parte da rede da Atuaserra são o poder público através das secretarias de turismo e os empreendimentos privados.

A Atuaserra consiste em uma Organização da Sociedade Civil de Interesse Público (OSCIP), ou seja, ela possui verbas do poder público, mas a gestão é privada, os recursos financeiros da Atuaserra provêm dos entes associados, de verbas de projetos municipais, estaduais e federais e da contribuição da iniciativa privada.

A necessidade de resgatar o turismo na Microrregião denominada Uva e Vinho deu origem à rede da Atuaserra, que ganhou um cunho estratégico, ou seja, uma rede planejada a partir do momento que busca articular público e privado na intervenção de ações turísticas para região. Em 1997 em decorrência das iniciativas de municipalização das ações do turismo, projeto iniciado em 1994 com o Programa de Municipalização do Turismo, a Atuaserra se consolidou como Governança Regional, instância que a partir de 2007, com o Plano Nacional do Turismo assumiu o papel de gestão da regionalização do turismo.

Ao agregar em sua dimensão organizacional, agentes do setor público e privado, que formalmente trabalham desde 1985, na gestão e execução das ações turísticas, a rede criada pela Atuaserra se concretiza em várias escalas espaciais de atuação levando em consideração a natureza das ações realizadas.

Segundo o Estatuto Social da Atuaserra (2009), a finalidade principal da associação é a promoção, coordenação, qualificação, capacitação e sensibilização do desenvolvimento do turismo regional, buscando fomentar a sustentabilidade ambiental, cultural e socioeconômica, resguardando a observância da livre iniciativa e liberdades fundamentais para todos.

De acordo com os dados fornecidos pela Atuaserra até fevereiro de 2014, os agentes sociais da sua rede, ou seja, o público associado e parceiro estava sistematizado em 24 secretarias de turismo dos municípios de Antônio Prado, Barão, Bento Gonçalves, Carlos Barbosa, Casca, Caxias do Sul, Cotiporã Farroupilha, Flores da Cunha, Garibaldi, Guaporé, Monte Belo do Sul, Nova Araçá, Nova Bassano, Nova Pádua, Nova Prata, Nova Roma do Sul, Protásio Alves, Santa Teresa, Santo Antônio do Palma, São Marcos, Serafina Corrêa, Veranópolis, Vila Flores. A (Figura 4) mostra a dimensão espacial da rede da Atuaserra em termos absolutos, ou seja, a localização dos municípios que estão na Microrregião Uva e Vinho, associados à Atuaserra. 

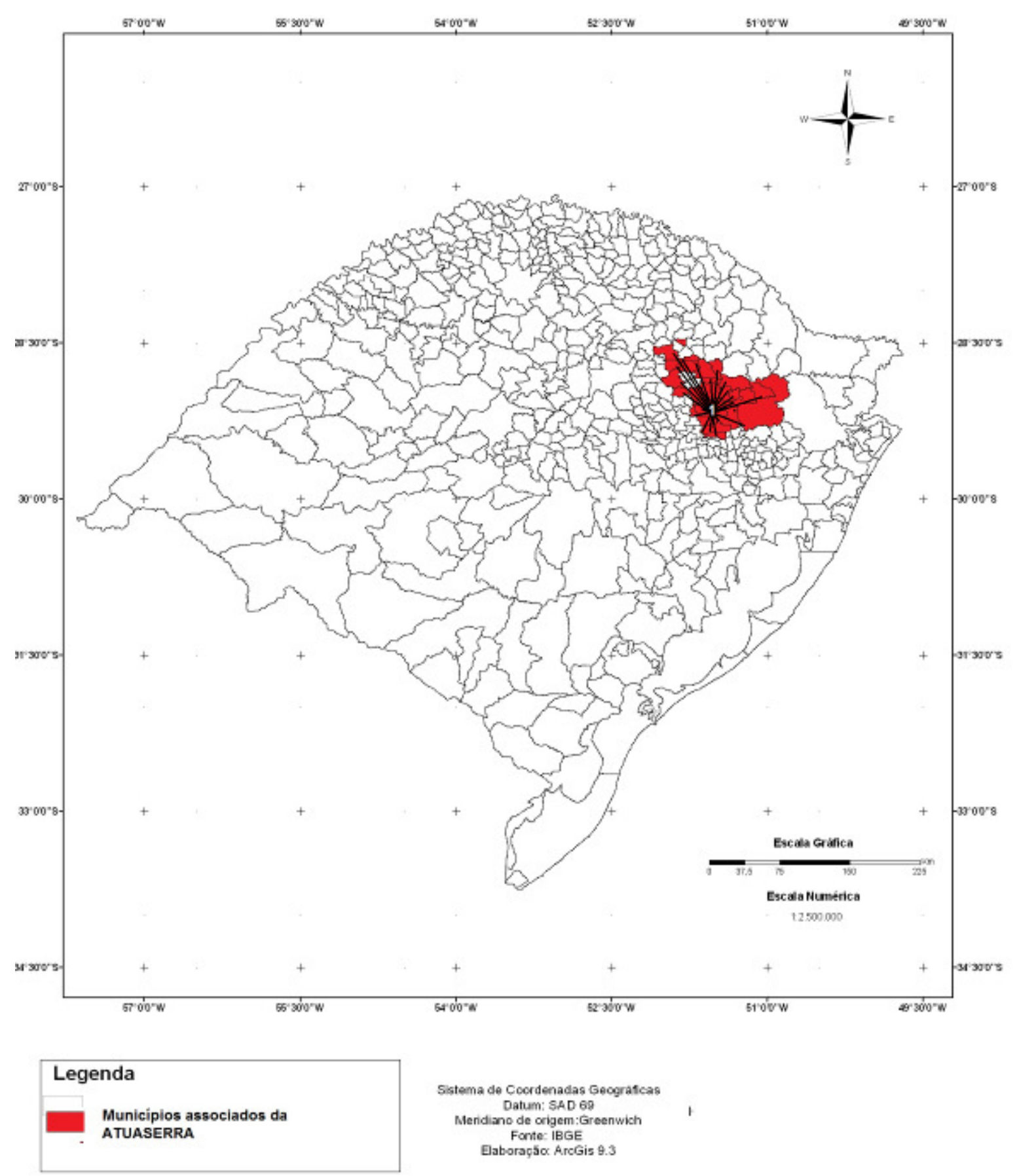

$$
\begin{aligned}
& \text { Sistema de Cocrdenadas Gecorafcas } \\
& \text { Menidiano de origem:Greenwich } \\
& \text { Fonte: IBGE } \\
& \text { Elaboraç5 } \alpha \text { A.reGis 9.3 }
\end{aligned}
$$

Figura 4: Dimensão espacial da rede da Atuaserra. Fonte: Adaptado pelo autor.

Figure 4: Spatial dimension of the network Atuaserra. Source: Adapted by the author.

A rede de abrangência territorial da Atuaserra está centralizada na cidade sede da Atuaserra, ou seja, Bento Gonçalves, configurando uma rede de característica solar, onde o centro emissor propaga suas ações para os municípios da região, ou seja, independente dos municípios serem associados da Atuaserra, os benefícios da ação da governança se faz presente nos 28 municípios da microrregião Uva e Vinho.

Além dos municípios associados a Atuaserra conta com 14 entidades e 17 parceiros divididos entre instituições de ensino, órgãos governamentais 
e iniciativa privada. O Quadro 1 sistematiza os agentes sociais da rede da Atuaserra.

Quadro 1: Agentes sociais da rede da Atuaserra. Fonte: Elaborado pelo autor.

Table 1:Social agents of Atuaserra network. Source: Elaborated by author.

\begin{tabular}{|c|c|}
\hline Associados & Parceiros \\
\hline Secretarias de Turismo dos municípios de: & Instituições de Ensino: \\
\hline $\begin{array}{l}\text { Antônio Prado, Barão, Bento Gonçalves, } \\
\text { Carlos Barbosa, Casca, Caxias do Sul, } \\
\text { Cotiporã Farroupilha, Flores da Cunha, } \\
\text { Garibaldi, Guaporé, Monte Belo do Sul, Nova } \\
\text { Araçá, Nova Bassano, Nova Pádua, Nova } \\
\text { Prata, Nova Roma do Sul, Protásio Alves, } \\
\text { Santa Teresa, Santo Antônio do Palma, São } \\
\text { Marcos, Serafina Corrêa, Veranópolis, Vila } \\
\text { Flores }\end{array}$ & $\begin{array}{l}\text { Faculdade de Integração do } \\
\text { Ensino Superior do Cone Sul } \\
\text { (FISUL); } \\
\text { Universidade de Caxias do Sul } \\
\text { (UCS); } \\
\text { Complexo de Ensino Cenecista; } \\
\text { FEEVALE; } \\
\text { Instituto Federal do Rio Grande } \\
\text { do Sul (IFRS); }\end{array}$ \\
\hline $\begin{array}{l}\text { Entidades privadas: } \\
\text { Associação dos Centros de Compras da Serra } \\
\text { Gaúcha; Associação do Comércio, Indústria e } \\
\text { Serviços de Carlos Barbosa, Associação } \\
\text { Comercial, Industrial, Serviços e Agropecuária } \\
\text { de Casca; Associação Comercial e Industrial } \\
\text { de Veranópolis; Associação de Joia e } \\
\text { Lingeries de Guaporé; Associação das } \\
\text { Pequenas e Médias Empresas de Garibaldi; } \\
\text { Associação de Produtores dos Vinhos dos } \\
\text { Altos Montes; Bento Convention Bureau, } \\
\text { Câmara de Dirigentes Lojistas de Nova Prata; } \\
\text { Câmara de Indústria, Comércio, Serviços e } \\
\text { Agropecuária de Antônio Prado; Câmara de } \\
\text { Indústria e Comércio de Garibaldi; Câmara } \\
\text { Cultural da Indústria, Comércio e Serviços de } \\
\text { Nova Prata, Sindicato de Hotéis, Bares, } \\
\text { Restaurantes e Similares de Garibaldi; } \\
\text { Sindicato de Hotéis, Bares, Restaurantes e } \\
\text { Similares Região Uva e Vinho; Sindilojas Nova } \\
\text { Prata. }\end{array}$ & $\begin{array}{l}\text { Organizações privadas: } \\
\text { Aventura Serra Gaúcha; } \\
\text { Instituto Marca Brasil; } \\
\text { Instituto Brasileiro do Vinho } \\
\text { (Ibravin); } \\
\text { Caminhos do Sertão } \\
\text { Cicloturismo; } \\
\text { Sindicato de Hotéis, } \\
\text { Restaurantes, Bares e } \\
\text { Similares) Região Uva e Vinho } \\
\text { (SHRBS); } \\
\text { Fundação Proamb; }\end{array}$ \\
\hline
\end{tabular}

Em articulação com os entes associados, a Atuaserra como instância de governança regional busca executar projetos que trabalham a educação ambiental, patrimonial e cultural como o Projeto Pulando Janelas, projetos do Programa Nacional de Aceleração do Crescimento (PAC), projetos de infraestrutura como a sinalização turística, projetos voltados para 0 fortalecimento de rotas turísticas, agroindústria e artesanato local, como o Projeto Fortalecendo o Roteiro Vales da Serra, Projeto Tecendo Fios, Embutidos da Serra Gaúcha. De acordo com a diretora executiva da Atuaserra, o foco principal do trabalho desenvolvido é a educação e 
qualificação da população, buscando dinamizar a ação turística de forma integrada com as esferas sociais econômicas e ambientais.

O papel estratégico da Atuaserra, como governança, consiste em ser uma instância, que faz parte da gestão da Política Nacional do Turismo e que tem a função de mediar ações entre o público e o privado, realizando o processo de validação dos projetos regionais de turismo. Para o melhor funcionamento desta mediação, há um consenso entre os informantes entrevistados de que o trabalho descentralizado é importante, mas que é necessária a articulação de ações para o fortalecimento regional.

\section{Conclusões}

Considerando que as redes e as governanças locais são elementos estratégicos na política Nacional do Turismo, estudos que abordam a referida temática, podem contribuir para avaliação dos processos de regionalização do turismo.

Portanto, ao sistematizar os principais dados da governança regional Atuaserra, é possível averiguar que o trabalho realizado desde a década de 1980 hoje se consolida regionalmente pela participação integrada do setor público e do privado, na promoção e execução do turismo na região. A rede da Atuaserra é formada espacialmente e socialmente por 24 secretarias de turismo, por 15 entidades associadas e entre as parceiras são 5 instituições de ensino e 7 instituições governamentais, que estão ligadas a diversos ministérios federais e secretarias estaduais. Esta diversidade de atores permite o fortalecimento da atividade turística da região, que é composta pelo município de Bento Gonçalves considerado pelo Ministério do Turismo um dos 65 destinos indutores do turismo.

Além disso, cabe destacar que como governança de turismo a Atuaserra têm a função legal junto ao Ministério do Turismo de sancionar os projetos turísticos construídos pela região.

Desta forma, a pequena exploração feita pelo presente estudo constatou que organizações locais que articulam esferas do setor público e privado criam cenários em que a rede de colaboração turística é mais ampla em termos espaciais. Pensando na sobreposição de distintas redes, cada membro da Atuaserra possui redes próprias, que propagam indiretamente ações que são gestadas no âmbito da governança.

No que se refere à coesão social e política da rede, é dever das governanças a mediação e construção de projetos turísticos, de acordo com a realidade regional, ações que a Atuaserra busca realizar junto com as secretarias municipais, para que ocorra o êxito e o reconhecimento de suas ações.

Existe a necessidade de um desdobramento maior sobre cada dimensão das redes criadas pela organização, no entanto, no espaço, deste estudo, o objetivo foi mostrar resumidamente a importância da instância de governança Atuaserra, na regionalização do turismo e a rede como uma possível categoria de análise, capaz de desvendar de forma mais abrangente, as diferentes escalas de atuação de uma governança. Esta 
breve exploração mostrou que a região é um instrumento político de planejamento espacial, mas que está articulada material e socialmente por instâncias que agregam diferentes esferas de poder, e que, portanto, não podem ser refutadas.

\section{Referências bibliográficas}

\section{ATUASERRA. Estatuto Social da Associação De Turismo da Serra Nordeste. 2009.}

BRAMANTI, A. From Space to Territory: Relational Development and Territorial Competitiveness. The GREMI Approach within the Contemporary Debate. In: Annals of Conference SMEs and districts: hybrid governance forms, knowledge creation \& Technology transfer... Castellanza, 5-7 November 1998. Disponível em:<http://hdrnet

.org/587/1/Links\%20BQ/48 From.space.to.territory.bramanti.pdf>. Acesso em: 14 mar. 2014.

BRASIL. Ministério do Turismo. Programa de regionalização do Turismo/Roteiros do Brasil - Diretrizes Políticas. Brasília, 2004. Disponível em: <http://nute.ufsc.br /bibliotecas/upload/diretrizes politicas programa regionalizacao.pdf >.

Acesso em: 22 maio. 2014.

BRASIL. Programa de Regionalização do Turismo - Roteiros do Brasil: Módulo Operacional 3: Institucionalização da Instância de Governança Regional. Brasília, 2007a. Disponível em: $<$ http://www.turismo.gov.br/export/sites/default/turismo/conselhos/conselhon acional/documentos conselho/modulo operacional 3 institucionalizacao da instancia de governanca regional.pdf>. Acesso em: 21 out. 2013.

BRASIL. Programa de Regionalização do Turismo - Roteiros do Brasil: Formação de Redes. Brasília, 2007b. Disponível em:< http://www.turismo.gov.br/export/sites/default/turismo/o ministerio/publicacoe s/downloads publicacoes/conteudo fundamental formacao de redes.pdf $>$. Acesso em: 20 out. 2013.

BRASIL. Programa de regionalização do Turismo - Diretrizes. Brasília, 2013. em: $<$ http://www.turismo.gov.br/export/sites/default/turismo/o ministerio/publicacoes/downloads publicacoes/PROGRAMA DE REGIONA LIZACAO DO TURISMO - DIRETRIZES.pdf>. Acesso em: 13 mar. 2014.

BRASIL. 65 Destinos Indutores do Desenvolvimento Turístico Regional. Brasília, 2014. Disponível em: <http://www.turismo.gov.br/regionalizacao/>. Acesso em: 10 mar. 2014.

CORRÊA, R.L. Dimensões de Análise das Redes Geográficas. In: CORRÊA, R.L. Trajetórias Geográficas. 4. ed. Rio de Janeiro: Bertrand. p.107-116. 2010. 
CORRÊA, R.L. Redes Geográficas: Reflexões sobre um tema persistente. Revista Cidades. v. 9, n.16, p. 200-218. 2012. Disponível em: $<$ http://revista.fct.unesp-

.br/index.php/revistacidades/article/viewFile/2378/2122. . . Acesso em: 21 set. 2013.

CHRISTALLER, W. Some considerations of tourism location in Europe: the peripheral regions underdeveloped countries recreation areas. Papers of the Regional Science Association, v.12, p. 95-105. 1963. Disponível em: $<$ http://onlinelibrary.wiley.com/doi/10.1111/j.1435-

5597.1964.tb01256.x/abstract>. Acesso em: 23 abr. 2014.

DIAS, L.C. Redes: emergência e organização. In: CASTRO, I.E.; GOMES, P. C.C.; CORRÊA, R.L. (orgs.). Geografia: Conceitos e temas. Rio De Janeiro: Bertrand Brasil, 1995. p.141-162.

Suelen de Leal Rodrigues: Universidade Federal do Rio Grande do Sul, Porto Alegre, RS, Brasil.

E-mail: slrgeo@yahoo.com.br.

Link para o currículo Lattes: http://lattes.cnpq.br/2051317613908004

Marcelino de Souza: Universidade Federal do Rio Grande do Sul, Porto Alegre, RS, Brasil.

E-mail:marcelino.souza@uol.com.br.

Link para o currículo Lattes: http://lattes.cnpq.br/8636371353890200

Data de submissão: 18 de agosto de 2014

Data de recebimento de correções: 16 de abril de 2015

Data do aceite: 21 de maio de 2015

Avaliado anonimamente 